\title{
Prevalence and Factors Influencing Neck Pain among Health Worker in Dentistry in Jordan
}

\author{
Wasfi A Al Hadid* \\ Ministry of Health, Al Zarqa Hospital, Jordan
}

Submission: March 14, 2018; Published: March 26, 2018

*Corresponding author: Wasfi A Al Hadid, Ministry of health, Al Zarqa Hospital, Jordan, Tel: 00962727069160; Email: drwasfihadeed@hotmail.com

\section{Abstract}

Neck pain among worker in dentistry is well documented in literature. In Jordan, there is a scarcity in reported prevalence and factors influencing the occurrence of neck pain in this health care category.

Aim: this study measured the prevalence of neck pain among workers in dentistry working in public health facilities in Jordan. Further, it examined the factors influencing the prevalence of reported neck pain.

Design: a cross sectional design.

Participants: Health care workers in dentistry working in clinics and hospitals in Jordan, including dentists, nurses, and dentistry workers.

Study Instrument: The first part of the study questionnaire includes participants' characteristics and asked about issues concerning the frequency and site of neck pain, associated movement or procedures, and whether pain is related to work. The second part is the neck disability index (NDI).

Results: 77 reported having neck pain with a mean age of 33.26 years, and the BMI averaged 24.85. Years of experience averaged 9.42. Most participants did not exercise and had average working hours of 41.09 /week. In addition, the average period of neck pain related to work was 3.170 , while the average work experience was more than nine years.

Discussion and Conclusion: The prevalence of neck pain in dentistry in Jordan is estimated as high. We recommend engaging dental workers in programs that promote better ergonometric positions and better adaptation to the neck pain causing positions and activities, and thus avoiding future development of a more complex health conditions.

Keywords: Dentistry; Neck Pain; NDI; Jordan

Abbreviations: NDI: Neck Disability Index;

\section{Introduction}

Dental practice is profession with health hazards, including neck pain. Working a dentist requires performing a range of procedures within restricted areas for extended hours [1]. The posture of the dentist and dentistry workers usually needs the use of vision, neck, back, and hands in positions that can least be described as discomforting and restraining [2]. The prevalence of musculoskeletal pain among this group of professionals has been well documented in literature [3,4]. Particularly, neck pain stands as a major complain that influences the quality of work as well as life of the practitioner [5]. Neck pain has been reported in the literature to occur in most dentists causing serious health consequences, such as work absenteeism, remarkable limitation in head and neck movement working $[6,7,8]$. Therefore, neck painhas become a serious public health problem among health practitioners, especially amongst practitioners in dentistry [9].
Although the exact pathophysiological causes are not explicitly explained [10], high rates of neck pain among dentists can be attributed to ergonomic factors related to the profession, including inappropriate posture and movements, frequent use of vibrating instruments and time spent with the patients while bending head and neck [11,12]. In one study in New Zealand, the reported prevalence of lower back pain reached $50 \%$, while neck pain and discomfort exceeded this percentage to more than $57 \%$ of the cases [13]. However, there are limited reporting on the prevalence of dental worker, other than the dentist, such as dental assistants and dental technicians. Because of the complex nature of the contributing factors associated with the prevalence of neck pain, studying this phenomenon becomes difficult. For this reason, the focus of many studies, including the present study, is to document the prevalence of neck pain using reliable and valid tools and the associated disabilities. In Jordan, the literature 
lacks reports on the case among Jordanian dental workers and practitioners. Therefore, this study was conducted to report the prevalence of neck pain among workers in dentistry working in public health facilities in Jordan. It also examined the factors influencing the prevalence of reported neck pain.

\section{Methods}

\section{Design}

This is a cross sectional study conducted in the period between January and March 2018.

\section{Setting and Participants}

All dentists and dentistry workers working within the Ministry of Health were eligible to participate in this study. The questionnaire was administered to 117 workers after explaining the study purpose and procedure. Participants were recruited from seven heath care centers and hospitals in Amman and Zarqa city. While 96 participants participated in the study representing a response rate of $82.1 \%$, only 77 reported having neck pain and completed the study questionnaire. Eligible participants were informed that confidentiality and anonymity will be maintained all through the process of data collection, analysis and dissemination of results. Published materials would not include any names or reference to employment status or setting of any individual participant.

\section{Study Instrument}

The first part of the study questionnaire includes participants' characteristics and asked about issues concerning the frequency and site of neck pain, associated movement or procedures, and whether pain is related to work. The second part is the neck

\section{Results}

\section{Characteristics of Study Participants}

Table 1: Characteristics of the participants $(\mathrm{N}=77)$.

\begin{tabular}{|c|c|c|c|c|}
\hline Factor & Mean (SD) & Category & $\mathbf{N}$ & Percent \\
\hline \multirow{2}{*}{\multicolumn{2}{|c|}{ Sex }} & Male & 30 & 39 \\
\hline & & Female & 47 & 61 \\
\hline \multirow{5}{*}{ Age } & \multirow{5}{*}{$33.26(9.944)$} & $20-25$ & 27 & 35.1 \\
\hline & & $26-30$ & 11 & 14.3 \\
\hline & & $31-35$ & 10 & 13 \\
\hline & & $36-40$ & 8 & 10.4 \\
\hline & & More than 40 & 21 & 27.3 \\
\hline \multirow{2}{*}{ BMI } & \multirow{2}{*}{$24.85(1.845)$} & Overweight & 48 & 62.3 \\
\hline & & Morbid Overweight & 29 & 37.7 \\
\hline \multirow{2}{*}{\multicolumn{2}{|c|}{ Exercising }} & Yes & 14 & 18.2 \\
\hline & & No & 63 & 81.8 \\
\hline \multirow{4}{*}{ Experience (Years) } & \multirow{4}{*}{$9.42(4.195)$} & 5-Jan & 35 & 45.5 \\
\hline & & 10-Jun & 14 & 18.2 \\
\hline & & 15-Nov & 6 & 7.8 \\
\hline & & More than 15 & 22 & 28.6 \\
\hline
\end{tabular}

disability index (NDI), which was adopted in the present study [14]. The NDI is a widely used scale measuring the prevalence and the impact of neck pain among workers.

\section{Neck Disability Index}

Based on the Oswestry Low Back Pain Index, the Neck Disability Index (NDI) consists of 10 questions that ask about the following issues concerning neck pain: pain intensity, personal care, lifting, reading, headaches, concentration, work, driving, sleeping, and recreation [14]. Item scores range from 0 (no disability) to 5 (total disability) with the maximum score of 50 . The NDI is usually transformed from a raw score of 50 to the percentile form and should require no more than 5 minutes to complete [15]. The NDI was validated for use in various countries, including countries of the Middle and Far East [15-19]. The internal consistency is reported to be high for the original English version and the other translations, including the Arabic version $[15,19]$. The cross-cultural adaptation has also been reported in the literature in cultures like the Turkish, Greek, and Arabic $[20,21]$. The internal consistency is reported to be high for the original English version and the other translations, including the Arabic version [19]. The validity and cross-cultural adaptation has also been reported in the literature in cultures like the Turkish, Greek, and Arabic [20,21].

\section{Ethical Considerations}

The study was approved by the Ethical Review Board at the Ministry of Health, Jordan. All participants approved to complete the study questionnaire voluntarily and knew they could withdraw anytime during the study. No personal data collected during the data collection procedure could identify the identity of the participant. 
JOJ Nursing \& Health Care

\begin{tabular}{|c|c|c|c|c|}
\hline Work hours/ Week & $41.09(7.062)$ & & & \\
\hline \multirow{3}{*}{ Period of experiencing neck pain } & \multirow{3}{*}{$3.170(1.130)$} & $1-2$ years & 59 & 76.6 \\
\hline & & 3-5 years & 17 & 22.1 \\
\hline & & Missing data & 1 & 1.3 \\
\hline \multirow{3}{*}{\multicolumn{2}{|c|}{ Specialization }} & Dentist & 48 & 62.3 \\
\hline & & Nurse & 14 & 18.2 \\
\hline & & Dental worker & 15 & 19.5 \\
\hline \multirow{4}{*}{\multicolumn{2}{|c|}{ Academic Degree }} & Diploma & 29 & 37.7 \\
\hline & & Baccalaureate & 28 & 36.4 \\
\hline & & Master & 16 & 20.8 \\
\hline & & $\mathrm{PhD}$ & 4 & 5.2 \\
\hline \multirow{2}{*}{\multicolumn{2}{|c|}{ Neck associated with work }} & Yes & 74 & 96.1 \\
\hline & & No & 3 & 3.9 \\
\hline \multirow{3}{*}{\multicolumn{2}{|c|}{ Common site(s) of pain }} & The neck and shoulders & 69 & 89.6 \\
\hline & & Along the neck sides & 4 & 5.2 \\
\hline & & Base of the neck & 4 & 5.2 \\
\hline \multirow{2}{*}{\multicolumn{2}{|c|}{ Taking analgesia (for several reasons) }} & Yes & 47 & 61 \\
\hline & & No & 30 & 39 \\
\hline \multirow{5}{*}{\multicolumn{2}{|c|}{ Taking analgesics for neck pain }} & None & 8 & 10.4 \\
\hline & & Daily & 10 & 13 \\
\hline & & Twice a week & 17 & 22.1 \\
\hline & & Once a week & 14 & 18.2 \\
\hline & & $\begin{array}{c}\text { Two to three times a } \\
\text { month }\end{array}$ & 28 & 36.4 \\
\hline \multirow{2}{*}{\multicolumn{2}{|c|}{ Seeking medical care for neck pain }} & Yes & 12 & 15.6 \\
\hline & & No & 65 & 84.4 \\
\hline \multirow{2}{*}{\multicolumn{2}{|c|}{ Sick leave for neck pain (previous year) }} & Yes & 7 & 9 \\
\hline & & No & 70 & 91 \\
\hline \multirow{2}{*}{\multicolumn{2}{|c|}{ Working status }} & Standing & 54 & 70.1 \\
\hline & & Sitting & 23 & 29.9 \\
\hline
\end{tabular}

The respondents were 96, of which 19 reported having no neck pain representing $19.8 \%$ of the total number of participants. The respondents who reported having neck pain and continued in the study were 30 males and 47 females with a mean age of 33.26 $( \pm 9.944)$ years. All participants were above the normal BMI with an average of $24.85( \pm 1.845)$. The average years of experience working in dentistry was $9.42( \pm 4.195)$. More than eighty per cent (63) of the participants reported they did not exercise or practice in any sport or fitness activities. We found that the average work hours per week 41.09 (7.062) divided on five days, with a minimum average of more than seven hours per day. More than half the participants were dentists $(48,62.3 \%)$. In addition, the average period of neck pain related to work was 3.170 (1.130), while the average work experience was more than nine years. Notably, neck pain episodes in $96.1 \%$ of the participants were related to work. Regarding site of neck pain, the majority reported that the most commonly felt pain is at neck and shoulders area followed by both sides of the neck and then the base of the neck. Interestingly, $61 \%$ of the participants took analgesics to minimize neck pain, and $43.3 \%$ reported using analgesics at least once a week. Table 1 summarizes the baseline characteristics of the participants in the study. Although this high percentage of participants reported experiencing neck pain that influenced their work, only .09\% (7) reported having sick leaves and $15.6 \%$ (12) sought medical care in the previous year.

\section{Prevalence and Impact of Work-Related Neck Pain}

As shown in Table 2, the NDI in this study had a high internal consistency value using Cronbach's Alpha coefficient ( $\alpha$.946), and the items on the scale alpha coefficient values ranging between .937 and .945 . In addition, we found that the mean scores of the NDI and its items were normally distributed. Results from NDI show that most participants experience neck pain restricted activities. The mean score on the NDI is $15.61( \pm 11.553)$ and it ranged between $1.351( \pm 1.058)$ for personal care and 1.766 $( \pm 1.213)$ for pain intensity. The mean scores on the NDI show that most participants experience mild to severe disability related to neck pain (Table 3). In addition, only 7.8\% (6) participants, who are dentist with an experience of more than 10 years, reported 
having complete disability and suffering neck after nearly each procedure.

Table 2: Results from the Neck Disability Index.

\begin{tabular}{|c|c|c|c|}
\hline & Mean & SD & 我 \\
\hline NDI & 15.61 & 11.553 & .946 \\
\hline Pain Intensity & 1.766 & 1.213 & .940 \\
\hline Personal Care & 1.351 & 1.058 & .943 \\
\hline Lifting & 1.558 & 1.114 & .939 \\
\hline Reading & 1.649 & 1.104 & .937 \\
\hline Headaches & 1.610 & 1.226 & .945 \\
\hline Concentration & 1.558 & 1.022 & .938 \\
\hline Work & 1.597 & 1.031 & .934 \\
\hline Driving & 1.533 & 1.324 & .941 \\
\hline Sleeping & 1.507 & 1.420 & .942 \\
\hline Recreation & 1.481 & 1.457 & .938 \\
\hline
\end{tabular}

Table 3: Interpretation of the Neck Disability Index scores.

\begin{tabular}{|c|c|c|}
\hline & Frequency & Percent \\
\hline No disability & 10 & 13.0 \\
\hline Mild disability & 35 & 45.5 \\
\hline Moderate disability & 12 & 15.6 \\
\hline Severe disability & 14 & 18.2 \\
\hline Complete disability & 6 & 7.8 \\
\hline
\end{tabular}

\section{Factors Influencing the Prevalence of Neck Pain}

There was a significant correlation between specialization and selected items of the NDI (Table 4). Prevalence of headaches, sleeping and recreation did not correlate with specialization ( $>$.05). The remainder of items correlated significantly with specialization of the participants. Dental workers achieved higher mean scores in all NDI items compared with the dentists and dental nurses, which reflected having greater impact on the items of the NDI. Furthermore, longer working hours per week were associated with greater impact on the ability of the participant in all NDI items, except for the prevalence of headaches and driving ( $>$.05). However, the NDI items did not correlate significantly with age, sex and years of experience in this study. In addition, NDI correlated significantly with the working status (i.e., sanding $v s$ sitting) with NDI items, expect for the recreation. The results have shown that working while standing has caused higher levels of neck pain-related difficulties, including increased pain intensity, difficulty in working, providing self-care and sleeping.

Table 4: Correlation between personal characteristics and NDI items.

\begin{tabular}{|c|c|c|c|c|c|c|}
\hline \multirow{2}{*}{ NDI item } & \multicolumn{2}{|c|}{ Specialization } & \multicolumn{2}{|c|}{ Weekly hours } & \multicolumn{2}{|c|}{ Working status } \\
\hline & Correlation & Sig. & Correlation & Sig. & Correlation & Sig. \\
\hline Pain Intensity & .211 & .065 & .393 & .003 & .546 & .001 \\
\hline Personal Care & .311 & .006 & .227 & .047 & .398 & .002 \\
\hline Lifting & .297 & .009 & .235 & .040 & .489 & .001 \\
\hline Reading & .302 & .008 & .327 & .004 & .232 & .032 \\
\hline Headaches & .171 & .137 & .195 & .089 & .448 & .003 \\
\hline Concentration & .360 & .001 & .265 & .020 & .352 & .035 \\
\hline Work & .362 & .001 & .260 & .022 & .645 & .001 \\
\hline Driving & .248 & .030 & .205 & .074 & .322 & .015 \\
\hline Sleeping & .186 & .105 & .249 & .029 & .297 & .003 \\
\hline Recreation & .071 & .538 & .315 & .005 & .065 & .063 \\
\hline
\end{tabular}




\section{Discussion}

This study explored the prevalence and the factors influencing work-related neck pain among dental health workers in different settings in Jordan. In this study, the prevalence, frequency and factors influencing neck pain among health worker in dentistry in Jordan were presented using the most frequently used instrument in literature, the NDI [10]. It has been widely reported that dentistry requires high accuracy and is frequently performed with cervical spine flexed forward and rotated in order to perform different tasks within the narrow oral cavity [22]. In addition to this awkward position, those workers usually spend extended durations and repeat these movements, which could eventually result in increased prevalence of high tension in the neck and accelerates the occurrence of pain [2]. In previously conducted studies from different countries, the prevalence of neck pain in dentistry was estimated between $10 \%$ and $35 \%$ among workers [23]. In the present study the corresponding estimate for workers, who experienced neck pain secondary to their working in dentistry, was higher (80.2\%). This finding is also higher than reported levels in earlier Saudi, Dutch and Australian studies, which reported neck pain prevalence between $66 \%, 51 \%$ and $57.5 \%$, respectively $[2,23,24]$. The position that the dentist and dentistry workers usually maintain during their work, such as bending while standing or sitting, can adversely affect the neck [25]. The use of portable ergonomic devices to investigate the position of those workers shown that those workers spend approximately half of their working time bending their heads down leading to severe spastic painful neck [26]. It is well documented in the literature that neck flexion in general causes neck pain [27]. In the present study, the correlation between items of the NDI and working status indicated that working while standing caused higher levels of negative experience than working while sitting. Similar findings have also been reported by other investigators [2,28].

Posture and movements, like twisting and bending, contributed to the higher risk of neck pain among participants, Based on our findings, working while sitting produces less neck pain due to a less stress, more angle freeing the neck, and a more neutral posture when compare with the standing position [11]. The degree of disability ranged between mild disability (45.5\%) and complete disability (7.8\%) representing a relatively high level of disability considering that most participants were young (mean age 33.26 year/old) and had experience less than 10 years. Additional warning findings is related to the high prevalence of no exercising (81.8\%) and not seeking medical care to relief pain (84.4\%). A study in Pakistan reported lower rates of disability using the NDI [29]. They found that $23.7 \%$ participants had mild pain, $28.2 \%$ had moderate episodic pain, $10.6 \%$ had moderate pain, $3.2 \%$ had severe episodic pain and $1 \%$ reported severe pain. Therefore, our findings could be considered as serious and might cause future concerns to health worker in the dentistry, including increased sick leaves and decreased productivity. When these factors have been identified then ergonomic solutions can be implemented [2]. It is believed that poor workplace ergonomics is among the key issues leading to higher levels of neck and shoulder pain among dentists [29]. In this study, age and sex did not have any significant impact on the prevalence of neck pain. This is probably as the age of the participants was less than 40 years of age reflecting a young population. It is reported in the literature that older dentists usually reported higher levels of pain related to work [30]. Other studies have shown that female dentists rated higher shoulder pain than the male dentists [2,31]. Results in this study could not be conclusive but are still indicative of the prevalence of neck pain among dental health workers in Jordan. One limitation of this study is the lack of objectivity in the process of measuring the extent and intensity of pain. This study depended mainly on a self-reporting questionnaire, which could did not underscore individual differences and personal perceived pain experience and it impact on the daily living.

The adoption of observational studies is recommended to achieve a more objective and representative results. Another limitation of the study could be the relatively small number of participants and the limited geographical area covered. Additionally, this study did not include psychosocial factors and their impact on the overall perceived neck pain. It should be considered in the future that studies address the longitudinal effect of neck pain and the risk factors associated with the prevalence of this type of pain among dental practitioners. A more comprehensive study that is based on assessing and documenting the physical and psychosocial impact of neck pain could be beneficial for researchers and decision-makers in the field.

\section{Conclusion and Recommendations}

This study showed an alarmingly high prevalence of neck pain, slightly higher than reported results in other studies. The high prevalence of neck pain among dental workers in Jordan underscores the importance of intervention in order to prevent the occurrence of further complications in the future. Increasing awareness and education programs should be focusing on the importance of early recording of signs and symptoms and training on the proper ergonomic positions to assist in promoting better bending and flexion with minimal negative impact. It is recommended that training programs and frequent detection of neck and shoulder pain caused by mal position be delivered to dental workers in different areas in Jordan. Another recommendation includes increasing the time between patients were dental workers could take sufficient relaxing and exercising to promote better ergonomics of the body.

\section{References}

1. Feng B, Liang Q Wang Y, Andersen LL, Szeto G (2014) Prevalence of work-related musculoskeletal symptoms of the neck and upper extremity among dentists in China. BMJ Open 4(12): e006451.

2. Al-Shehri Z, Al Zoughool M (2018) Prevalence and risk factors of musculoskeletal symptoms among dental students and dental practitioners in Riyadh City, Saudi Arabia. Archives of Environmental \& Occupational Health 73(1): 56-63. 
3. Alghadir A, Zafar H, Iqbal ZA (2015) Work-related musculoskeletal disorders among dental professionals in Saudi Arabia. J Phys Ther Sci 27(4): 1107-1112.

4. Gaowgzeh RA, Chevidikunnan MF, Al Saif A, El-Gendy S, Karrouf G, et al. (2015) Prevalence of and risk factors for low back pain among dentists. J Phys Ther Sci 27(9): 2803-2806.

5. Kose G, Hepguler S, Atamaz F, Oder G (2007) A comparison of four disability scales for Turkish patients with neck pain. J Rehabil Med 39(5): 358-362.

6. Cote P, Van der Velde G, Cassidy JD, Carroll LJ, Hogg Johnson S, et al. (1976) Bone and Joint Decade 2000-2010 Task Force on Neck Pain and Its Associated Disorders.

7. Cote P, Van der Velde G, Cassidy JD, Carroll LJ, Hogg Johnson S, et al (2008) The burden and determinants of neck pain in workers: results of the Bone and Joint Decade 2000-2010 Task Force on Neck Pain and Its Associated Disorders. Spine 33(4 Suppl): S60-S74.

8. Cramer H, Lauche R, Langhorst J, Dobos, GJ, Michalsen A (2014) Validation of the German version of the Neck Disability Index (NDI) BMC Musculoskeletal Disorders 15: 91.

9. Mohammad ZJ (2011) musculoskeletal disorders: back and neck problems among a sample of Iraqi dentists in Baghdad city. J Baghdad Coll Dent 23(4): 90-95.

10. Macdermid JC, Walton DM, Avery S, Blanchard A, Etruw E, et al. (2009) Measurement properties of the neck disability index: A systematic review. J Orthop Sports Phys Ther 39(5): 400-417.

11. Al-Mohrej OA, AlShaalan NS, Al Bani WM, MasuadI EM, Almodaimegh HS (2016) Prevalence of musculoskeletal pain of the neck, upper extremities and lower back among dental practitioners working in Riyadh, Saudi Arabia: a cross-sectional study. BMJ Open 6: e011100.

12. Ayatollahi J, Ayatollahi F, Ardekani AM, Bahrololoomi R, Ayatollahi J (2012) Occupational hazardsto dental staff. Dent Res J (Isfahan) 9(1): 2-7.

13. Samotoi A, Moffat SM, Thomson WM (2008) Musculoskeletal symptoms in New Zealand dental therapists: Prevalence and associated disability. N Z Dent J 104(2): 49-53.

14. Vernon H, Mior S (1991) the neck disability index: a study of reliability and validity. J Manipulative Physiol Ther 14(7): 409-415.

15. Shaheen AAM, Omar MTA, Vernon H (2013) Cross-cultural adaptation, reliability, and validity of the Arabic version of neck disability index in patients with neck pain. SPINE 38(10): E609-E615.

16. Nakamaru K, Vernon H, Aizawa J, Koyama T, Nitta O (2012) CrossCultural adaptation, reliability and validity of the Japanese version of the neck disability index. Spine (Phila Pa 1976) 37(21): E1343-1347.

17. Uthaikhup S, Paungmali A, Pirunsan U (2011) Validation of Thai versions of the neck disability index and neck pain and disability scale in patients with neck pain. Spine (Phila Pa 1976) 36(21): E1415-E1421.
18. Wu S, Ma C, Mai M, Li G (2010) Translation and validation study of Chinese versions of the Neck Disability Index and the Neck Pain and Disability Scale. Spine (Phila Pa 1976) 35(16): 1575-1579.

19. Yao M, Sun YL, Cao ZY, Dun RL, Yang L (2015) A systematic review of cross-cultural adaptation of the neck disability index. Spine (Phila $\mathrm{Pa}$ 1976) 40(7): 480-490.

20. Telci EA, Karaduman A, Yakut Y, Aras B, Simsek IE, et al. (2009) The cultural adaptation, reliability, and validity of neck disability index in patients with neck pain: A Turkish version study. Spine 34(16): 17321735.

21. Trouli MN, Vernon HT, Kakavelakis KN, Antonopoulou MD, Paganas AN, et al. (2008) Translation of the Neck Disability Index and validation of the Greek version in a sample of neck pain patients. BMC Musculoskeletal Disorders 9: 106.

22. Abiodun-Solanke I, Agbaje J, Ajayi D, Arotiba J (2010) Prevalence of neck and back pain among dentists and dental auxiliaries in Southwestern Nigeria. Af J of Med and Medical Sci 39(2): 137-42.

23. Droeze EH, Jonsson H (2005) Evaluation of ergonomic interventions to reduce musculoskeletal disorders of dentists in the Netherlands. Work 25(3): 211-220.

24. Leggat PA, Smith DR (2006) musculoskeletal disorders self-reported by dentists in Queensland, Australia. Aust Dent J 51(4): 324-327.

25. Morse T, Bruneau H, Dussetschleger J (2010) musculoskeletal disorders of the neck and shoulder in the dental professions. Work 35(4): 419-429.

26. Varmazyar S, Amini M, Kiafar S (2012) Ergonomic evaluation of work conditions in Qazvin dentists and its association with musculoskeletal disorders using REBA method. J Islam Dent Assoc IRAN 24: 182-187.

27. McNee C, Kieser JK, Antoun JS, Bennani H, Gallo LM, et al. (2013) Neck and shoulder muscle activity of orthodontists in natural environments. J Electromyogr Kinesiol 23(3): 600-607.

28. Rafie F, Zamani Jam A, Shahravan A, Raoof M, Eshkandarizadeh A (2015) Prevalence of upper extremity musculoskeletal disorders in dentists: Symptoms and risk factors. J Environ Public Health.

29. Ijaz A, Khan I, Ahmed A, Sadiq S (2016) Frequency of neck pain among dentists. POJ 8(2): 89-93.

30. Soares JJF, Sundin 0, Grossi G (2003) Age and musculoskeletal pain. Int J Behav Med 10(2): 181-190.

31. Muralidharan D, Fareed N, Shanthi M (2013) Musculoskeletal disorders among dental practitioners: Does it affect practice?. Epidemiol Res Int: $1-6$. 
(C) (P) This work is licensed under Creative Commons Attribution 4.0 License DOI: 10.19080/JOJNHC.2018.07.555706

\section{Your next submission with Juniper Publishers} will reach you the below assets

- Quality Editorial service

- Swift Peer Review

- Reprints availability

- E-prints Service

- Manuscript Podcast for convenient understanding

- Global attainment for your research

- Manuscript accessibility in different formats

( Pdf, E-pub, Full Text, Audio)

- Unceasing customer service

Track the below URL for one-step submission https://juniperpublishers.com/online-submission.php 